\title{
The genetics of wing pattern elements in the polyphenic butterfly, Bicyc/us anynana
}

\author{
GRAHAM J. HOLLOWAY, PAUL M. BRAKEFIELD \& STANS KOFMAN \\ Section of Evolutionary Biology, Department of Population Biology, University of Leiden, Schelpenkade 14a, $2313 \mathrm{ZT}$ \\ Leiden, The Netherlands
}

\begin{abstract}
The tropical butterfly, Bicyclus anynana, is highly polyphenic in response to seasonal changes (temperature and rainfall) in Malawi. The wing pattern varies considerably between the wet and dry season forms, particularly with respect to the background colour and the size of many of the wing pattern elements (e.g. eyespots). A selection experiment was carried out to determine the heritability of one of the ventral wing surface eyespots. The degree of genetic covariation among the various polyphenic ventral surface pattern elements and two non-polyphenic dorsal surface eyespots was also investigated. Selection to both increase and decrease the relative size of the second eyespot on the ventral surface was successful and indicated a heritability of more than 0.4 . Other eyespots and the transverse wing band on the ventral surface all showed correlated responses. On the dorsal surface only the second eyespot showed a correlated response to selection. The results indicate that response to selection occurred at two levels: (i) the genes affecting the size of the eyespot directly and (ii) the eyespot biochemical determination mechanism. The fact that not all of the dorsal surface features showed correlated responses suggests that subtle differences may exist between the ways in which the production of eyespots on the ventral and dorsal surface is controlled.
\end{abstract}

Keywords: Bicyclus anynana, development, eyespot, genetics, Lepidoptera, selection.

\section{Introduction}

Insect wings are intricate structures, both in terms of morphology and the localized cell function differentiation across the wing surface that produces colour pattern. A considerable amount of effort has been devoted to analysing insect wing design and the complex and numerous deformations that occur during flight are frequently interpreted as optimal (Norberg, 1972; Wootton, 1981; Brodskiy \& Ivanov, 1983; Ennos, 1988). This requires that genetic variation is available to achieve fine-grained adaptation, so that each component of the wing can evolve largely independently. Although the optimization view is pervasive, several authors maintain that morphological differentiation is controlled by a small number of genes (GarcíaBellido, 1983; Raff \& Kaufman, 1983) or by a limited number of developmental outcomes (Goodwin, 1984). Weber (1992), however, demonstrated that finegrained adaptation of components of insect wings is possible by selecting for structural change in a very small area of Drosophila wing. Weber (1992) also argued that his findings were compatible with theories of wing cell differentiation based on concentration thresholds in gradients of morphogens produced by localized clusters of cells (French, et al., 1976; Nijhout, 1990). Indeed, cuticle grafts have shown that certain groups of cells can retain their original positional identity and can produce features, such as eyespots, in abnormal postions (Locke, 1959; Nijhout, 1980).

The African genus Bicyclus (Lepidoptera, Satyrinae) contains over 70 species (Condamin, 1973), many of which show seasonal variation with respect to wing colour pattern (Brakefield \& Reitsma, 1991). During the wet season many Bicyclus species possess large eyespots (possibly to deflect vertebrate predator attacks (Brakefield \& Larsen, 1984)) and transverse bands. At this time the butterflies are active and utilize the prevailing flush of green vegetation for breeding. During the dry season, most of the vegetation dies back and the butterflies adopt a far more sedentary behaviour. To facilitate predator avoidance, a cryptic wing pattern develops (Brakefield \& Larsen, 1984) in which the eyespots and the transverse band are substantially reduced in size and the background colour changes to resemble dead leaves. The reaction norm 
(Stearns, 1989) of the ventral wing surface colour pattern in B. anynana and B. safitza appears to be more or less unbounded (Gabriel \& Lynch, 1992) and continuous across the temperature range studied (Brakefield \& Reitsma, 1991; Windig, 1992). This suggests that these species are sufficiently plastic to achieve an optimal solution under all conditions encountered (Gabriel \& Lynch, 1992). Of course, as the temperature changes, all of the wing pattern elements associated with the polyphenism (Shapiro, 1976) change more or less in unison. Several of the elements, such as eyespots, are structurally alike and it is likely that they are influenced by very similar, if not the same, developmental system and morphogen (Nijhout, 1991). If this is the case, one would predict that the subsequent evolution of the wing pattern elements in these species could not easily occur with a high degree of independence, in contrast with Weber's (1992) assertion (see above).

The study reported here aimed to determine the heritability of a single wing pattern component and to investigate the degree of genetic covariance among various other pattern components in $B$. anynana. Selection experiments were carried out on a single component on the polyphenic ventral wing surface pattern, but the influence of the selection on the nonpolyphenic dorsal wing surface features was also considered.

\section{Materials and methods}

\section{Rearing methods}

The experimental insects were derived from a stock which was initiated using 80 gravid females collected from Nkhata Bay, Malawi, in 1988. Large populations have been maintained in the laboratory always numbering several hundred individuals. This was important to avoid the erosion of genetic variation through sampling effects (Frankel \& Soulé, 1981). All generations were reared at $28^{\circ} \mathrm{C}\left( \pm 1^{\circ} \mathrm{C}\right), 85$ per cent $( \pm 5$ per cent) relative humidity $(\mathrm{RH})$ and $12: 12$ light:dark. Larvae were reared in mesh cages $(50 \times 50 \times 50 \mathrm{~cm})$ on approximately 3 -week-old maize plants grown in the laboratory. Plants were renewed when almost devoid of leaf material and the length of time between renewal depended on the size of the larvae. Newly formed pupae were removed from their sites of attachment (usually on plant stems) and placed in a Petri dish, one dish per day. The pupae were left in these environmental conditions for 2 days of ensure that the future wing pattern of the butterfly was determined as the wet season form (Brakefield \& Reitsma, 1991). Thereafter they were transferred to a temperature of $18^{\circ} \mathrm{C}\left( \pm 2^{\circ} \mathrm{C}\right)$ to slow down development. This measure enabled us to synchronize emergence better by returning the pupae to warm conditions once most of the larvae had pupated.

The freshly emerged butterflies were sexed and a number of wing pattern elements (see below) were measured on all females. No effort was made to retain virginity and the females were allowed to mate at random. Having measured the wing characters, each female was assigned a unique number for later identification. The number was carefully written on the ventral surface of the left hindwing using a fine-tipped permanent marker pen. Marking in this way never increased mortality in the females. The adult butterflies were fed on banana until the selection was made. The selected females were placed in a clean cage with 50 randomly chosen males to ensure that all of the females could mate if they had not already done so. All remaining butterflies were discarded. A number of week-old maize plants were placed in the cage for oviposition. After a week these plants were removed from the cage and fresh maize plants were offered for another week. Adult butterflies were fed continuously on banana. After 2 weeks the selected females and the accompanying males were removed. Larvae emerging on both sets on plants were reared through to adults as described above.

\section{Selection experiments}

The selection experiments were carried out on the size of the second eyespot relative to wing length on the ventral surface of the left forewing (see below). Pilot experiments have shown that this eyespot is generally well formed and neat and, therefore, is relatively easy to measure. Measurements were made using a micrometer inserted in an eye piece of a Wild binocular microscope. Three characteristics were measured: (i) width of the second eyespot on the ventral surface of the left forewing $(25 \times)$, (ii) width of the fifth eyespot on the ventral surface of the left hindwing $(25 \times)$ and (iii) the length of the left forewing $(6 \times)$ (see Fig. 1). The absolute eyespot size was always closely correlated with wing length. To avoid simply selecting for increased wing length, selection was carried out on the ratio of width of second eyespot to wing length.

Two selection lines were developed: one to increase the ratio of second eyespot width to wing length and a second to decrease the ratio. Each selection line was initiated using separate samples of insects from the stock population. The two lines were reared asynchronously as large larvae eat substantial quantities of maize and the wing pattern data collection was time consuming. When all of the butterflies had emerged 


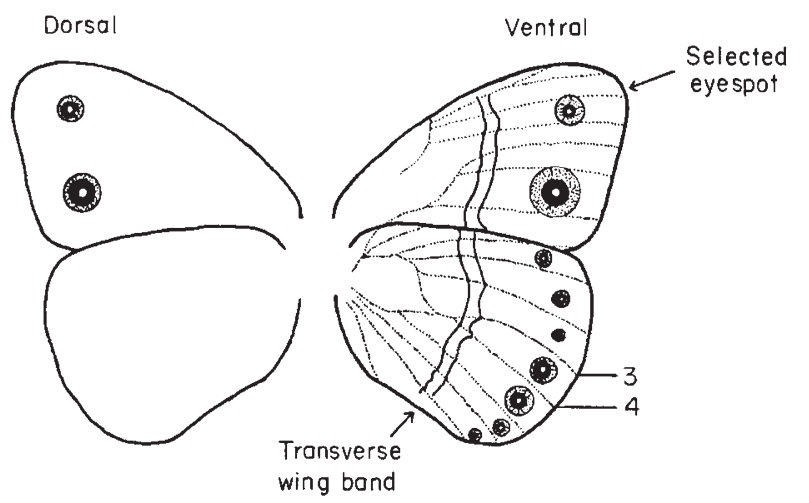

Fig. 1 Schematic illustration showing the positions and relative sizes of eyespots and transverse wing band normally found on the dorsal and ventral wing surfaces of Bicyclus anynana. Hindwing veins 3 and 4 are indicated, the junction of which was used in the measurement of band width (see text).

from pupae and had been measured, the data were entered into a computer and the values of the selection character ranked. The top (or bottom) 40 female butterflies were selected to initiate the next generation.

\section{Wing pattern analysis}

Selection was continued until the shapes of the selection lines could be assessed and good divergence of the selected character was achieved. After termination of selection a further generation from each line was reared under the above conditions, but no selection was carried out. These generations produced samples of insects from the two lines for a more general assessment of the impact of the selection on the wing pattern as a whole.

Each eyespot consists of a white focus surrounded by a black ring which in turn is bordered by a gold ring. For each eyespot examined, the widths of the gold ring, the black ring and the focus were measured. The measurements were made at $25 \times$ magnification and were performed on characters on the left wings (see Fig. 1). The eyespots measured were: (i) the second forewing ventral eyespot, (ii) the fifth forewing ventral eyespot, (iii) and second forewing dorsal eyespot, (iv) the fifth forewing dorsal eyespot and (v) the fifth hindwing ventral eyespot. The presence or absence of small, first, third and fourth eyespots on the forewing was also assessed. A four-point scoring system was used ranging from $4=$ complete eyespot separated from adjacent larger eyespots, to $1=$ obvious bulge in gold ring of second or fifth eyespot. A further extra eyespot in cell 8 of the hindwing was also sometimes noted. This eyespot, when present, is always separate

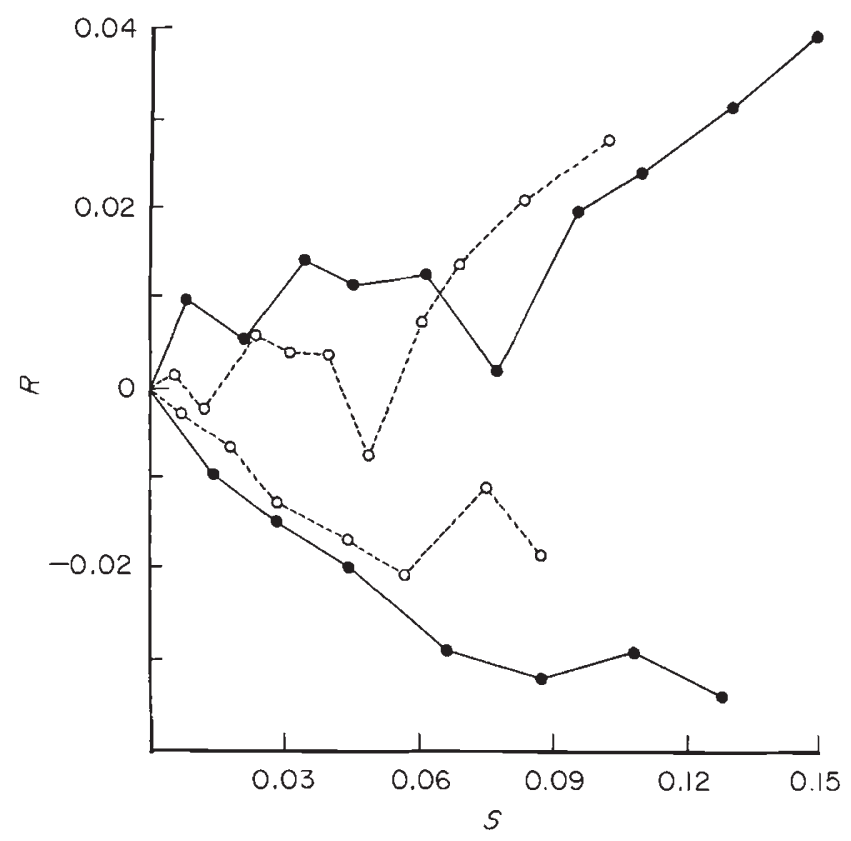

Fig. 2 Cumulative response $(R)$ to selection of the size of the forewing second eyespot (relative to wing length) $(\bullet-\bullet)$ plotted on cumulative selection coefficient $(S)$. The correlated response to selection of the size of the fifth hindwing eyespot (relative to wing length) $\left(\mathrm{O}----_{-}\right)$is also shown.

from the eyespot in cell 7 , but a similar four-point scoring system was used ranging from $4=$ complete and well formed eyespot to $1=$ few coloured wing scales only. The width of the transverse band on the ventral surface of the hindwing is always difficult to measure due to the indistinct nature of the outer edge of the band. The inner edge of the band is generally much sharper. As an index of band width the distance from the inner edge of the band to the junction of veins 3 and 4 was measured at $50 \times$ magnification. This index has been found to correlate very closely with band width (J. Windig, unpublished data). Finally, the length of the forewing at $6 \times$ magnification was determined and the sex of the butterfly was recorded.

All analyses were carried out using Minitab.

\section{Results}

\section{Selection experiments}

Selection was carried out on an average of $231( \pm 16$ S.E.) females each generation. The high line was continued for 10 generations and the low line was continued for seven generations. Figure 2 shows the results of the selection procedures. The selected character (second forewing eyespot width over forewing length) showed a good response in both directions. At the end of selection the two populations showed no overlap in the size 
of the selected character. It is also apparent that the fifth eyespot on the hindwing showed a highly correlated response in both directions (Fig. 2). The dip in the upward selected lines at $F_{6}$ was the result of a temporary food shortage. The effect of this was to reduce the average size of the butterflies and to induce more of a dry season appearance. The heritability of the second forewing eyespot can be estimated from the slope of the line (Falconer, 1989). Only females were selected so the regression coefficients need to be multiplied by two. The estimated heritabilities of the second forewing eyespot from the upward and downward selection lines were 0.421 and 0.410 , respectively. However, close inspection of Fig. 2 reveals that neither of the two selection lines is linear. The rate of response in the upward line steadily increased, whilst the rate of response in the downline decreased. The above heritabilities, therefore, can only be taken as a rough guide and it is also inappropriate to attach standard errors to the estimate (cf. Hill, 1972). A possible explanation accounting for the shapes of the line and the highly correlated response of the fifth hindwing spot is developed below.

\section{Wing pattern analysis}

Ninety butterflies from the low line and 120 butterflies from the high line were used for the final wing pattern analysis. The lengths of the forewings of males in the high and low lines were 19.15 and $18.73 \mathrm{~mm}$, and for females 21.30 and $21.39 \mathrm{~mm}$, respectively. There was no significant difference (ns) between the lines $\left\langle F_{1,205}=0.9\right.$, ns $)$, but the wing lengths of the sexes did differ $\left(F_{1,205}=189.5, P<0.001\right)$. Table 1 shows the results of the analysis of the eyespots and transverse band. The widths of all eyespots differed between the two lines at the end of the selection procedure (in all cases $P<0.001$ ), except for the fifth eyespot on the dorsal wing which showed no significant difference between the two lines. Also included in Table 1 is a breakdown of each spot into the proportion of the total width occupied by gold, black and white scales. It is apparent that a change in the width of an eyespot was usually associated with change in the structure of the eyespot. The changes in the proportions of the total eyespot widths occupied by the various colours was nearly always highly significant. These structural changes occurred in all eyespots except the second eyespot on the dorsal surface. Curiously, the structure of the fifth eyespot on the dorsal wing surface was also different between the two lines even though the width of the eyespot did not change significantly. The selection procedure also had an effect on the width of the transverse band on the ventral surface of the hindwing
Table 1 Eyespot size and structure in male and female adult butterflies from the high $(\mathrm{H})$ and low $(\mathrm{L})$ lines. The eyespots analysed were (i) second ventral forewing $(2 v)$, (ii) fifth ventral forewing (5v), (iii) second dorsal forewing (2d), (iv) fifth dorsal forewing (5d) and (v) fifth ventral hindwing (5h)

\begin{tabular}{|c|c|c|c|c|c|c|c|}
\hline \multirow[b]{2}{*}{ Sport } & \multirow[b]{2}{*}{ Line } & \multirow[b]{2}{*}{ Sex } & \multirow[b]{2}{*}{ Width } & \multirow[b]{2}{*}{$R$} & \multicolumn{3}{|c|}{ Proportion of width } \\
\hline & & & & & Gold & Black & White \\
\hline \multirow[t]{5}{*}{$2 v$} & $\mathrm{H}$ & 0 & 2.266 & 0.121 & 0.467 & 0.347 & 0.186 \\
\hline & & q & 2.623 & $\begin{array}{l}0.123 \\
* * *\end{array}$ & $\begin{array}{l}0.387 \\
* * *\end{array}$ & $\begin{array}{l}0.434 \\
* * *\end{array}$ & $\begin{array}{l}0.178 \\
* * *\end{array}$ \\
\hline & & & & & $+t+$ & 林 & \\
\hline & $\mathrm{L}$ & 0 & 1.122 & 0.059 & 0.414 & 0.273 & 0.312 \\
\hline & & $q$ & 1.201 & 0.056 & 0.361 & 0.348 & 0.291 \\
\hline \multirow[t]{5}{*}{$5 v$} & $\mathrm{H}$ & 0 & 3.416 & 0.182 & 0.381 & 0.429 & 0.190 \\
\hline & & q & 4.770 & $\begin{array}{l}0.223 \\
* * *\end{array}$ & $\begin{array}{l}0.279 \\
* * *\end{array}$ & $\begin{array}{l}0.557 \\
*\end{array}$ & $\begin{array}{l}0.164 \\
* * *\end{array}$ \\
\hline & & & & $+t+$ & $t+t$ & $\dagger \dagger$ & $+t+$ \\
\hline & $\mathrm{L}$ & O" & 3.087 & 0.161 & 0.309 & 0.477 & 0.214 \\
\hline & & ㅇ & 3.903 & 0.185 & 0.253 & 0.549 & 0.197 \\
\hline \multirow[t]{5}{*}{$2 \mathrm{~d}$} & $\mathrm{H}$ & 0 & 1.967 & 0.105 & 0.343 & 0.515 & 0.141 \\
\hline & & $q$ & 2.281 & $\begin{array}{l}0.107 \\
* * *\end{array}$ & 0.314 & 0.561 & 0.125 \\
\hline & & & & $\dagger$ & $t+\dagger$ & 抿 & $\dagger$ \\
\hline & $\mathrm{L}$ & 0 & 1.153 & 0.060 & 0.352 & 0.505 & 0.144 \\
\hline & & q & 1.487 & 0.070 & 0.299 & 0.578 & 0.134 \\
\hline \multirow[t]{5}{*}{$5 d$} & $\mathrm{H}$ & $0^{*}$ & 2.817 & 0.150 & 0.256 & 0.573 & 0.171 \\
\hline & & q & 4.111 & 0.192 & $\begin{array}{l}0.208 \\
* * *\end{array}$ & $\begin{array}{l}0.634 \\
* * *\end{array}$ & $\begin{array}{l}0.158 \\
* * *\end{array}$ \\
\hline & & & & $t+t$ & $+\dagger \dagger$ & t十† & 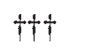 \\
\hline & $\mathrm{L}$ & 0 & 2.735 & 0.143 & 0.219 & 0.629 & 0.152 \\
\hline & & $q$ & 3.874 & 0.182 & 0.184 & 0.683 & 0.132 \\
\hline \multirow[t]{5}{*}{$5 \mathrm{~h}$} & $\mathrm{H}$ & 0 & 2.692 & 0.144 & 0.315 & 0.516 & 0.169 \\
\hline & & q & 3.304 & $\begin{array}{l}0.154 \\
* * *\end{array}$ & $\begin{array}{l}0.273 \\
* * *\end{array}$ & $\begin{array}{l}0.566 \\
* * *\end{array}$ & 0.161 \\
\hline & & & & & $t+\dagger$ & †十 & \\
\hline & $\mathrm{L}$ & 0 & 2.098 & 0.110 & 0.253 & 0.582 & 0.165 \\
\hline & & q & 2.275 & 0.107 & 0.239 & 0.601 & 0.160 \\
\hline
\end{tabular}

The width is in millimetres and $R=$ the width of the eyespot divided by the length of the wing. * Significant difference between lines, $\uparrow$ Significant difference between sexes. * and $\dagger$ $P<0.05,{ }^{* * *}$ and $+\dagger \dagger P<0.001$.

as the low line had a significantly narrower band than the high line (divided by wing length) $\left\langle F_{1,203}=21.5\right.$, $P<0.001)$.

Table 1 also summarizes differences between the sexes. Male Bicyclus are smaller than females and so have smaller eyespots, but even when corrected for wing length many sex differences still remain. In the second ventral forewing and fifth ventral hindwing spots there are no significant differences between the 
sexes. A small, but statistically significant, difference exists between the sexes in the second dorsal eyespot $\left(F_{1,199}=4.05, P=0.046\right)$ but there are large differences between the sexes for the fifth ventral and dorsal forewing eyespots $\left(F_{1,205}=31.9, P<0.001\right.$ and $F_{1,203}=56.5, P<0.001$, respectively). All of the eyespots show structural differences between the sexes; in other words, the proportions of the eyespot widths occupied by gold, black and white scales differ between the sexes. A consistent difference between the sexes is that in every eyespot in both lines the width of the gold ring is proportionally greater in males than in females; the width of the black ring in females is always proportionally greater than in males, and the width of the white pupil is proportionally greater in males than females. However, the wing pattern components in the two sexes nearly always responded to selection in a similar manner. Of the numerous tests carried out on the data summarized in Table 1 only four, proportion gold and proportion black in the fifth ventral eyespot in the high and low lines, yielded a small sex by line interaction.

Table 2 shows ratios of high line over low line for mean width gold scales, mean width black scales and mean width white scales (male and female values combined). These figures provide an indication of the effect of selection on the various eyespot components. The second forewing ventral eyespot components show the largest differences between the two lines, but this is not surprising because selection was carried out on this eyespot. However, the relative difference between the lines for the gold ring is greater than that for the black ring which in turn is greater than for the white pupil. The same pattern is shown by the components of the fifth forewing ventral eyespot, although the differences are not so great. With the remaining ventral eyespot on

Table 2 High line value divided by low line value after cessation of selection for width of eyespot over wing length $(R)$ and the length of spot diameter occupied by gold, black and white scales. The eyespots examined were (i) second forewing ventral $(2 \mathrm{v})$, (ii) fifth forewing ventral (5v), (iii) second forewing dorsal (2d), (iv) fifth forewing dorsal $(5 \mathrm{~d})$ and $(v)$ fifth hindwing ventral $(5 h)$. Males and females are combined

\begin{tabular}{lllll}
\hline & & \multicolumn{3}{l}{ Response of scales coloured } \\
\cline { 3 - 5 } Spot & $R$ & Gold & Black & White \\
\hline $2 \mathrm{v}$ & 2.119 & 2.102 & 1.944 & 1.277 \\
$5 \mathrm{v}$ & 1.169 & 1.164 & 1.141 & 1.038 \\
$2 \mathrm{~d}$ & 1.636 & 1.620 & 1.605 & 1.543 \\
$5 \mathrm{~d}$ & 1.055 & 1.045 & 1.055 & 1.258 \\
$5 \mathrm{~h}$ & 1.379 & 1.367 & 1.281 & 1.364 \\
\hline
\end{tabular}

the hindwing the difference between the white pupil in the two lines is greater than expected, but again the change in the gold ring was greater than that for the black ring. The structural changes in the dorsal eyespots were quite different from the ventral surface. The second dorsal forewing eyespot showed a good correlated response to selection but the structure of the eyespot did not change significantly. The fifth dorsal forewing eyespot width did not change significantly, but the structure of the eyespot did. However, in this eyespot the white changed relatively more than the black band which, in turn, changed more than the gold band, i.e. completely opposite to the ventral surface eyespot changes.

Table 3 summarizes the occurrence of extra spots in the two lines following selection. Overall, more extra eyespots appeared in the high line than the low line. Several butterflies in the high line of both sexes produced extra eyespots on the ventral surface forewing cell 3. The distribution of the categories of eyespots did not differ between the sexes $\left(\chi_{3}^{2}=0.2\right.$, ns $)$. In the low

Table 3 The numbers of extra eyespots in high $(\mathrm{H})$ and low (L) line butterflies of each sex in forewing cells 1,3 and 4 on the ventral surface $(1 v, 3 v$, and $4 v$, respectively) and the dorsal surface ( $1 \mathrm{~d}, 3 \mathrm{~d}$ and $4 \mathrm{~d}$, respectively). The degree of eyespot development is categorized using a four-point system (see text), 4 being fully formed and separated from other eyespots

\begin{tabular}{|c|c|c|c|c|c|c|c|}
\hline \multirow[b]{2}{*}{ Spot } & \multirow[b]{2}{*}{ Line } & \multirow[b]{2}{*}{ Sex } & \multicolumn{5}{|l|}{ Category } \\
\hline & & & 0 & 1 & 2 & 3 & 4 \\
\hline $1 v$ & $\begin{array}{l}\mathrm{H} \\
\mathbf{L}\end{array}$ & $\begin{array}{l}0 \\
8\end{array}$ & $\begin{array}{l}\text { No spots } \\
78 \\
\text { No spots }\end{array}$ & 6 & 2 & & \\
\hline $1 \mathrm{~d}$ & & & No spots & & & & \\
\hline $3 v$ & $\begin{array}{l}\mathrm{H} \\
\mathbf{L}\end{array}$ & $\begin{array}{l}0 \\
0 \\
0 \\
0\end{array}$ & $\begin{array}{l}24 \\
60 \\
\text { No spots } \\
64\end{array}$ & $\begin{array}{l}3 \\
6\end{array}$ & $\begin{array}{l}3 \\
8\end{array}$ & $\begin{array}{r}4 \\
12 \\
3\end{array}$ & \\
\hline $3 d$ & $\begin{array}{l}\mathrm{H} \\
\mathbf{L}\end{array}$ & $\begin{array}{l}0 \\
0 \\
0 \\
0\end{array}$ & $\begin{array}{l}31 \\
82 \\
\text { No spots } \\
66\end{array}$ & 1 & & $\begin{array}{l}3 \\
2\end{array}$ & 1 \\
\hline $4 v$ & $\begin{array}{l}\mathrm{H} \\
\mathbf{L}\end{array}$ & $\begin{array}{l}0 \\
9 \\
0 \\
9\end{array}$ & $\begin{array}{l}\text { No spots } \\
59 \\
\text { No spots } \\
44\end{array}$ & $\begin{array}{l}25 \\
12\end{array}$ & 1 & 1 & 2 \\
\hline $4 d$ & $\begin{array}{l}\mathrm{H} \\
\mathbf{L}\end{array}$ & $\begin{array}{l}0 \\
9 \\
0 \\
9\end{array}$ & $\begin{array}{l}32 \\
70 \\
\text { No spots } \\
63\end{array}$ & 1 & $\begin{array}{l}1 \\
6\end{array}$ & 7 & $\begin{array}{l}1 \\
2\end{array}$ \\
\hline
\end{tabular}


line, only three females produced extra eyespots in the third forewing cell on the dorsal surface with no males. However, all of these dorsal eyespots were well formed and separate from the second eyespot. Only a few butterflies produced extra eyespots on the dorsal forewing surface in cell 3, but again there was no apparent difference between the sexes. There was a substantial difference between the sexes in the expression of forewing cell 4 eyespots with no males producing eyespots on the ventral surface in cell 4 in either of the selection lines. In contrast, many females produced extra eyespots, with relatively more females in the low line producing extra eyespots than the high line and also more eyespots in the low line showing a greater degree of separation from the fifth eyespot. On the dorsal surface, only two high line males produced extra cell 4 eyespots whilst 20 females expressed an extra eyespot at this position. However, most of the extra dorsal cell 4 eyespots were found in the high selection line.

\section{Discussion}

Rather few studies have been carried out on the genetics of eyespot size and structure in butterflies. The notable exception is the work on the genetics of wing pattern elements in the meadow brown butterfly, Maniola jurtina (Brakefield, 1984; Brakefield \& Noordwijk, 1985). It was found that both eyespot size and number were highly heritable characters. It is apparent from the response to selection that eyespot size in $B$. anynana is also highly heritable (Fig. 2).

$B$. anynana is an extremely polyphenic butterfly (Brakefield \& Reitsma, 1991) and the ventral wing surface patterns in wet and dry season butterflies are remarkably different. The seasonal forms appear to be produced in direct response to the development period of the fifth larval instar and early pupal stage (Windig, 1992). Many of the features of butterfly wing patterns are thought to be determined in the early pupae by the diffusion of morphogens across the surface of the wing (Nijhout, 1980; 1990; 1991; French \& Brakefield, 1992). The results of manipulation of certain groups of cell on the surface of the wing suggest that they produce particular chemicals which diffuse away from the source to form information gradients (Nijhout, 1980). The concentration of the chemical encountered by cells surrounding each source determines their eventual colour. It is easy to envisage how spot formation conforms to this scenario but it has been argued that all patterns on a butterfly's wing, including marginal chevrons and bands, are derived from responses to diffusion gradients from point (or line) sources (Nijhout, 1990; 1991). A modelling approach had indicated that these sources, including the areas of cells corresponding with the white pupils of the eyespots, may produce a substance that interacts with a second (threshold) compound (see Nijhout, $1990 ; 1991)$. It has also been suggested that the foci may be acting as sinks rather than sources; the cells degrading a morphogenic substance (see also French \& Brakefield, 1992). Presumably, the wet and dry season phenotypes are produced by altering the amounts of these chemicals released and the additive and/or interactive effect of the compounds stimulates particular wing cells to produced a wet or dry season colour pattern.

If the colour components of a butterfly wing are formed through a reaction to the concentration of one or more morphogens, it may be difficult to elicit purely local changes in response to selection as was achieved by Weber (1992) using Drosophila wings. Figure 2 clearly shows that whilst the selected character changed other components also changed, although the degree of response in correlated characters was not as great as with the selected character (Tables 1 and 2). It is possible that the selection procedure affected several factors simultaneously. In changing the size of an eyespot we may have selected for a change in the amount of morphogen produced by each source (assuming that each source produces the same chemical). The amount of any interacting 'threshold' morphogen(s) present over the (competent) wing surface could also have been altered. Changes in the amount of one or more chemicals produced could affect many wing pattern elements simultaneously and, indeed, all of the ventral surface components measured changed in a correlated manner. However, if this was the whole story, we would expect all of the eyespot changes to have shown perfect correlation, which they did not. The second eyespot changed to a relatively greater extent than all of the other eyespots (Table 2). Another possible explanation is that genetic variation exists for morphogen sensitivity in the cells surrounding each source and that increased (and decreased) sensitivity was selected for. Similarly, selection may have changed the activity of specific sources of sinks. Evidence for such a localized effect comes from the correlated response of the second dorsal forewing eyespot. This eyespot showed a large difference between the two lines and, of course, it lies in the dorsal surface wing cell corresponding to the second ventral eyespot. This suggests that a qualitative change may have occurred specifically in this area of the wing as a result of selection.

Females are on average lighter in colour than males and, following the same argument outlined above for the two wing surfaces, it is possible that male and female wing patterns are influenced by different biological mole- 
cules or by different concentrations of the same molecules, or that male and female wings have different threshold values (Nijhout, 1990; 1991). Although both sexes responded to selection in a similar manner, Table 1 highlights many differences between the sexes in size and structure of the wing pattern elements. Further differences between the sexes can be seen in Table 3 for the occurrence of extra eyespots, although eyespot expression did not differ between the sexes in all cells. Forewing cell 3 eyespot was as likely to appear in a male as a female, but forewing cell 4 eyespot was much more frequently noted in females than males. Brakefield \& Noordwijk (1985), working with M. jurtina, described a positive relationship between the expression of extra eyespots and the size of the eyespots that were always expressed. With $B$. anynana, such a relationship also exists except when the extra eyespot is well formed and completely separated from other eyespots. These perfect extra eyespots may be influenced by the inheritance of single genes (P. M. Brakefield, unpublished data). The extra eyespots are also, presumably, morphogen sources, but normally too little material is produced (or degraded) to elicit a developmental phenotypic reaction. It is not clear why or how the expression of these extra eyespots varies among wing cells. Usually more extra eyespots were found in the high line, except for forewing cell 4 and then only on the ventral surface, whereas the low line produced relatively more and better formed eyespots than the high line. No explanation can, at present, be offered to account for this observation.

Further evidence that the selection affected the determination of the eyespots at the biochemical level comes from the shapes of the selection lines (Fig. 2) and the absolute changes in the widths of the three colour components of each spot (Table 2). The diffusion gradient of a morphogen from a focus would be expected to adopt the shape depicted in Fig. 3 (cf.

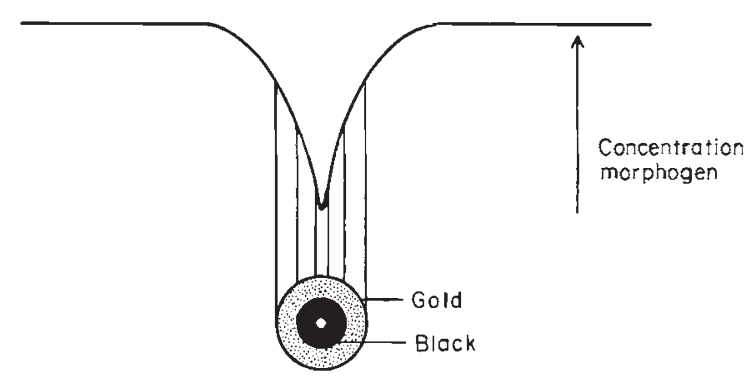

Fig. 3 Diagram illustrating the production of eyespots according to a sink model. The cells of the white focus of the eyespot produce a substance that breaks down a generally distributed morphogen. The changing concentration of the morphogen away from the focus codes for the production of different coloured scales.
French \& Brakefield, 1992). Selection on the amount of morphogen produced could produce an exponential response in relative eyespot size. In other words, selection to increase the size of the eyespot would produce an exponentially increasing line, while selection to decrease the size of the eyespot would produce an exponentially decreasing response. This expectation is borne out in Fig. 2. One would also expect the outer ring of an eyespot to change relatively faster than inner rings (see Fig. 3). An inspection of Table 2 shows that this frequently occurred, at least on the ventral surfaces of the wings. The changes that occurred in the dorsal wing eyespots were quite different. The width of the second dorsal forewing eyespot changed but the structure of the eyespot did not. The fifth dorsal forewing eyespot did not change significantly in size but the structure did. However, this structural change followed a different pattern to the changes showed by the ventral eyespots following selection. This again suggests that there may be differences between the processes of pattern determination on the two wing surfaces in B. anynana.

The width of the transverse band changed along with the eyespots in response to selection. The appearance of the band is very different from the eyespots and is, presumably, influenced by a different physiological process. Unfortunately, very little is as yet known about the determination of the band structure.

Although the modifications in the wing pattern elements were varied, some of our observations lend support to Weber's (1992) assertion that genetic variation exists which influences small components of an insect wing independently. Thus, although very intricate, an insect's wing can, to a large extent, evolve towards an optimum form without hinderance through powerful constraints between the component parts. This argument apparently does not cover both the morphology of the wing and the clusters of cells responsible for pattern determination equally well, as suggested by Weber (1992). Although many foci may be involved in determining the colour pattern, the morphogen(s) may be common to many systems (see Nijhout, 1991). Thus since the same biochemical pathway is operational, the functional activity of one focus is likely to be highly correlated with that of others, at least within a given character set (e.g. eyespot, transverse wing band, marginal chevrons). In other words, in the context of the present study, it may be very difficult to select successfully for a change in the size of one specific eyespot without influencing the other eyespots which are expressed. However, the foci are sufficiently independent from each other epigenetically to enable a considerable diversity in eyespot patterns across taxa (Nijhout 1990; 1991). This apparent lack of develop- 
mental constraints over longer evolutionary time scales may be accounted for partly by the more localized effects of alleles of single major genes at an earlier developmental stage when the presence or absence of specific active foci is determined.

\section{References}

BRAKEFIELD, P. M. 1982. Ecological studies on the butterfly Maniola jurtina in Britain. I. Adult behaviour, microdistribution and dispersal. J. Anim. Ecol., 51, 713-726.

BRAKEFIELD, P. M. 1984. The ecological genetics of quantitative characters in Maniola jurtina and other butterflies. In: The Biology of Butterflies, Symp. Roy. Ent. Soc. Lond., 11, pp. 167-190. Academic Press, London.

BRAKEFIELD, P. M. AND LARSEN, T. B 1984. The evolutionary significance of dry and wet season forms in some tropical butterflies. Biol. J. Linn. Soc., 22, 1-12.

BRAKEFIELD, P. M. AND van NOORDWIJK, A. J. 1985. The genetics of spot pattern characters in the meadow brown butterfly Maniola jurtina (Lepidoptera: Satyridae). Heredity, 54, 275-284.

BRAKEFIELD, P. M. AND ReITSMA, N. 1991. Phenotypic plasticity, seasonal climate and the population biology of Bicyclus butterflies (Satyridae) in Malawi. Ecol. Entomol., 16, 291-303.

BRODSKIY, A. K. AND IVANOV, V. D. 1983. Functional assessment of wing structure in insects. Entomol. Rev., 62, 35-52.

COndamin, M. 1973. Monographie du genre Bicyclus (Lepidoptera, Satyridae). Memoires de l'Institut Fondamental d'Afrique Noire, IFAN, Dakar.

ENNOS, A. R. 1988. The importance of torsion in the design of insect wings. J. Exp. Biol., 140, 137-160.

FALCONER, D. S. 1989. Introduction to Quantitative Genetics. 3rd edn, Longman, London.

FRANKEL, O, H. AND SOUlÉ, M. E. 1981. Conservation and Evolution. Cambridge University Press, Cambridge.

FRENCH, V. AND BRAKEFIELD, P. M. 1992. The development of eyespot patterns on butterfly wings: morphogen sources or sinks? Development, 116, 103-109.
FRENCH, V., BRYANT, P. J. AND BRYANT, s. v. 1976, Pattern regulation in epimorphic fields. Science, 193, 969-980.

GABRIEL, W. AND LYNCH, M. 1992. The selective advantage of reaction norms for environmental tolerance. J. Evol. Biol., $\mathbf{5}, 41-59$.

GARCtA-BELLIDO, A. 1983. Comparative anatomy of cuticular patterns in Drosophila. In: Goodwin, B. C., Holder, N. and Wylie, C. C. (eds). Development and Evolution, Cambridge University Press, Cambridge, pp. 227-255.

GoODWIN, B. C. 1984. Changing from an evolutionary to a generative paradigm in biology. In: Pollard, J. W. Evolutionary Theory: Paths into the Future. Wylie, New York, pp. 99-120.

HILL, W. G. 1972. Estimation of realised heritability from selection experiments. II. Selection in one direction. Biometrics, 28, 767-780.

LOCKE, M. 1959. The cuticular pattern in an insect, Rhodnius prolixus. Stal. J. Exp. Biol., 36, 459-477.

NIJноUт, н. F. 1980. Pattern formation on lepidopteran wings: determination of an eyespot. Devl. Biol., 80, 267-274.

NIJHouT, H. F. 1990. A comprehensive model for colour pattern formation in butterflies. Proc. Roy. Soc. Lond. B., 239, $81-113$.

NiJHout, H. F. 1991. The Development and Evolution of Butterfly Wing Patterns. Smithsonian Institute Press, Washington and London.

NORBERG, R. A. 1972. The pterostigma of insect wings an inertial regulator of wing pitch. J. Comp. Physiol., 81, 9-22.

RAFF, R. A. AND kAUfMAN, T. C. 1983. Embryos, Genes, and Evolution. Macmillan, New York.

Shapiro, A. M. 1976. Seasonal polyphenism. Evol. Biol., 9, 259-333.

STEARNS, S. C. 1989. Trade-offs in life-history evolution. Funct. Ecol., 3, 259-268.

WEBER, K. E. 1992. How small are the smallest selectable domains of form? Genetics, 130, 345-353.

WINDIG, J. J. 1992. Seasonal polymorphism in Bicyclus safitza, a continuous reaction norm. Neth. J. Zool., in press.

wootron, R. J. 1981. The mechanical design of insect wings. Sci. Am., 263, 114-120. 